\title{
Study of Business Communication Algorithms, Service Scenario Design and Data Valuation Statistics (Innovation, Business Model)
}

\section{Introduction ${ }^{1}$}

The structure of a forecast algorithm applies the principles of evolution found in nature to finding optimal problem-solving solutions. In a forecast algorithm, the problem is encoded in a series of portions of information that are manipulated by the algorithm; in a 'systematic algorithm'2, the decision variables and problem functions are used directly. Most business management products are based on forecast algorithms. A forecast algorithm for optimisation is different from 'usual' optimisation methods in several ways. Trying to make multi-objective optimisation decisions, many traditional methods optimise the objective deployment into a single objective. In those cases, the obtained solution is highly sensitive and used in the optimisation process demanding that the user has knowledge about the underlying problem. Moreover, in making multi-objective decisions, business designers may be interested in a set of maximum target points, instead of a single one. Although Service Scenario Design has been implemented by top management and tried to make several multi-objective decisions, it seems that the in terms of mathematical objectives, the algorithm may present some business opportunity. In this study, we investigate how the proof-of-principle results obtained by several decisions used by top management and others suggest that the proposed method can be extended to higher-dimension and more difficult multi-objective decisions. A few suggestions for the extension and application of the algorithm are also discussed.

\section{Business Communication Algorithms}

Business Communication Algorithms (BCAs) are often well-suited for optimisation decisions involving several, often conflicting objectives. Since

${ }^{1}$ Mihail Kitanovski, International business and management consultant.

2 J.M. Carroll (ed.), Scenario-Based Design: Envisioning Work and Technology in System Development, John Wiley \& Sons, Inc. New York 1995. 
new business models are implemented, various forecast approaches to multi-objective optimisation have been developed that can identify multiple solutions concurrently in a single run. However, the few comparative studies of different methods presented to date remain mostly qualitative and are often restricted to a few approaches. In this study, several multi-objectives are used quantitatively where the extent of data concerning decision-making is taken as a basis. The purpose is to introduce a new forecast approach to multi-criteria optimisation which combines several features of the previous multi-objective and is characterised by:

1) implementing simple solutions,

2) evaluating a management relation dependent on the number of interested parties

3) preserving inter-company behaviour, and

4) incorporating a clustering procedure in order to reduce non-conformities.

The principal results obtained as regards two artificial decisions as well as a larger problem, a synthesis of a digital hardware-software multiprocessor system, suggest that BCA can be very effective in sampling and distributing the generated solutions using the trade-off method.

In different industries as well as many areas of scientific research, data collected often contain a number of responses of interest for a chosen set of exploratory variables. Optimisation of such multi-variable multi-response systems is a challenge well suited to genetic algorithms as global optimisation tools. One such example is the optimisation of management meetings with the required absolute and relative sensitivity for detecting data using targets such as Business targets. High throughput synthesis and screening methods can be used to accelerate Business information discovery and optimisation; however, an important practical consideration for successful optimisation of materials for arrays and other applications is the ability to generate adequate information from a minimum number of Business activities ${ }^{3}$.

Here, we present a case study to evaluate the efficiency of a novel Business forecast model-based multi-response approach that enables the optimisation of a coating while minimising the number of Business activities. Business plans are integrated into the Business activities and simultaneously model the information properties. We illustrate this novel procedure for information optimisation by testing the algorithm on six-step activities:

- Data collection

- Identification (asking relevant questions - database)

- Decision node (application engine)

- Statistic and algorithm

${ }^{3}$ N. Benvenuto, G. Cherubini, Algorithms for Communications Systems and their Applications, 1st ed., John Wiley \& Sons Ltd, The Atrium, Southern Gate, Chichester, West Sussex 2002. 
- Verification (verifying the final information)

- Validation (finishing the process).

The response variables of the forecasting activities have been optimised based on application criteria for micro- and macro-database information and Data Valuation Statistics. The optimisation is achieved by exploring less than $2 \%$ of the possible Business activities, resulting in the identification of the most influential compositional variables. The use of such a model to optimise control factors of a product or process is illustrated and the proposed approach is shown to be a promising tool for simultaneously optimising and modelling multivariable multi-response systems.

The reconfiguration of the existing Business chain network is essential to retain their competitive edge. On the strategic level, however, even if we focus on a quantitative criterion such as cost, it is not unusual that various costs involved in a Business chain and data valuation statistic network cannot easily be aggregated into the overall cost because of their imprecision, indeterminate nature and uncertainty. Furthermore, there are other qualitative criteria to evaluate the performance of a Business chain and data valuation statistic network. In such complex situations, such as an overall evaluation, a simple weighted sum of criteria is not adequate. Instead, the frequently used outranking analysis is the most suitable. So far, various variants of meta-forecasting model algorithms have been proposed, which are called Advanced Business Algorithm. These, however, have a weakness because of their arbitrariness and at the same time difficulty of coding. These approaches are very logical and scientific but due to the sensitivity of human intuition and experience they may prove imperfect in the context of decision-making in the real world. The best approach is to decide as to an optimal number of warehouses and optimal Business chain and data valuation statistic network with a weight form the market. On an illustrative application, we conducted a Business design scenario and data of the evaluation of various reconfiguration alternatives of the warehouses distributed all over a wide region.

\section{Service Scenario Design (SSD)}

Solving and optimisation of decisions activities with multiple (often conflicting) objectives is, generally, a very difficult goal. Forecast algorithms were initially extended and applied in the late 1980s in an attempt to stochastically solve decisions of this generic class. During the past decade, a variety of Multi-Objective techniques have been proposed and applied to many scientific and engineering applications. The purpose of our discussion is to rigorously define multi-objective optimisation decisions and certain related concepts, present an SSD classification scheme and evaluate the variety of contemporary SSDs. Current SSD theoretical developments 
are evaluated; specific topics addressed include main processes functions, management ranking, data sharing, meeting restriction and then Business actions. Since the development and application of SSDs is a dynamic and rapidly growing activity, we focus on key analytical insights based upon critical SSD evaluation of current forecast and applications. Recommended SSD designs are presented, along with conclusions and recommendations for future business work ${ }^{4}$.

For the successful calculation, we implemented the following key functionalities, which enhance the existing proof of concept of D2EM Consulting, named Service Scenario Design. We apply a Service Scenario Design to generate a new business model while randomly combining tasks according to their input/output objects, dependencies and gateways. This choice significantly influences the performance. The resulting genomes are feasible, but rarely optimal in the first iteration. Besides, we can force the Service Scenario Design to create only feasible genomes to facilitate an automated initial process design. Thereby, we explicitly consider the semantics of Service Scenario Design and their semantics in business operations and, thereby, extend the overall solution space compared to the existing proof of concept.

\subsection{Leadership Cluster Segmentation}

Leadership Cluster Segmentation usually involves two sets of variables: (1) the initial variables (referred to as the base variables), which are used in developing the original segments to identify the value, and (2) the dynamic variables, used to profile or target the customers. The manager's goal is to utilise these two sets of variables in the most efficient manner. Pragmatic managerial interests recognise the underlying need to start shifting from methodologies that secure highly precise value-based segments but may be of limited practical use as they provide less targetable segments. Consequently, the imperative is to shift toward newer segmentation approaches that provide greater focus on targetable segments while maintaining homogeneity. This requires dual objective segmentation, which is a combinatorically difficult problem. Hence, we propose and examine a new forecast methodology based on genetic algorithms to address this problem.

Table 1. Forecast outperforms of existing methods

\begin{tabular}{|c|c|c|}
\cline { 2 - 3 } \multicolumn{1}{c|}{} & Regular Model & SSD via BCA model \\
\hline 1 Segmentation & Less than 10 & 15 \\
\hline 2 Segmentation & 8 & Less than 10 \\
\hline Model & \multicolumn{2}{c|}{ Variable $=600$ values (companies) in $190 \mathrm{~d}}$. \\
\hline
\end{tabular}

${ }^{4}$ T. Koller, M. Goedhart, D. Wessels, Valuation: Measuring and Managing the Value of Companies, 6th ed., McKinsey \& Company Inc., John Wiley \& Sons, New Jersey 2015. 
We show, on the basis of a large-scale D2EM Consulting simulation and a case study, that the proposed approach consistently outperforms the existing methods for a wide variety of problem instances. We can obtain statistically significant and managerially important improvements in value-based segments. Moreover, the proposed methodology provides a set of good solutions, unlike the existing methodologies that provide a single solution. We also show how these good solutions can be used to plot an efficient Service Scenario Design. Finally, we present useful insights that would help managers in implementing the proposed solution approach effectively.

Table 2. Service Scenario Design and forecasting

\begin{tabular}{|l|c|c|c|}
\cline { 2 - 4 } \multicolumn{1}{c|}{} & Business Process & $\begin{array}{c}\text { Leadership } \\
\text { process }\end{array}$ & $\begin{array}{c}\text { Data Valuation } \\
\text { Statistics }\end{array}$ \\
\hline Forecast Algorithm 01 & Highly needed & As relevant & $100 \%$ \\
\hline Forecast Algorithm 02 & Highly needed & Highly needed & $100 \%$ \\
\hline Forecast Algorithm 03 & $\begin{array}{c}\text { Mathematical and } \\
\text { statistical approach }\end{array}$ & As relevant & $50 \%$ \\
\hline Forecast Algorithm 04 & Stochastic method & Highly needed & $50 \%$ \\
\hline
\end{tabular}

Service Scenario Design allows for limiting several depths to avoid unnecessarily complex process designs with multiply duplicated gateways and/or tasks not contributing to better solutions. As varying crossover and/ or mutation rates are critical to the success, we start with a high probability and a low crossover probability that will decrease or increase respectively by:

$$
\mathrm{BCA}=\sum_{k=0}^{n} \mathrm{a}^{n+1}
$$

$a$ represent the planned meeting, where $\mathrm{n}$ represents the real number of meetings. Thereby, we ensure a broad exploration of the solution space at the beginning and a narrow solution space exploitation at the end, fostering the convergence of the business model. Multi-criteria are a very explicit model that deploys the information related to the process performance dimension time (i.e. fixed completion time per task) to foster the use of exclusive and parallel gateways. We finally calculate the Service Scenario Design as an individually weighted average of the task-related cash flows and time estimations based on user preferences. This calculation covers the time and cost of the process performance dimensions.

\subsection{Forecasting Model}

As the best solution is close to the boundary between the solution space of feasible and infeasible designs, we gain the best solution from both sides. That is the reason for adopting and introducing a forecast factor as a fore- 
cast adjustment in business processes, through overly complex solutions. Besides, we ensure at least one feasible solution per month through the Service Scenario Design.

Business chain and data valuation statistic have attracted a lot of attention from most companies. Among them, to maintain their competitiveness it is essential to reconfigure the Business chain and data valuation statistic network. On the strategic level, however, even if we focus on a quantitative criterion such as cost, there are situations when it is not easy to aggregate various costs into the overall cost, because of their imprecision, indetermination and uncertainty. Furthermore, other qualitative criteria must be taken into consideration for evaluating the performance of the Business chain and data valuation statistic network. In these complex situations, the forecasting model approach which has been frequently used is the most suitable. However, the general approach does not often include opinions and the intuition of the decision-maker. This study is focused on the Leadership Hierarchy Process. It has been implemented in the evaluation of several reconfiguration alternatives of the Business points distributed in a wide region. We adjust the leadership decision concept to calculate the weight of the decision-maker's opinion. And then, the weight from the forecasting model forecast segmentation is adapted in a genetic algorithm. It is expected that this approach will play a proper human-machine role in real-world decision-making 5 .

\section{Evaluation Model Through Predictable Data}

One of the most critical issues facing Business chain and data valuation statistic managers in today's globalised and highly-uncertain business environment is how to proactively deal with risks that might cause serious severances and distortions of data flows in a Business chain and data valuation statistic. This work proposes a simulation-based forecast algorithm approach for deriving the operational planning of global Business network and data valuation statistics from systematic risk management which proactively deals with the forecast consequences of random and hazardous risk events in sourcing, production, distribution, and transportation in an integrated way. The proposed approach incorporates the performance of minimum a 4 (four) cycled management review in order to link quantity and the reorder point and three response coefficients as decision variables with potential risks. Over the last 16 years, the proposed approach has been successfully applied to many industrial examples by more than $600 \mathrm{com}-$ panies. The results of the computational study show that systematic risk management of global Business chain and data valuation statistics using the

${ }^{5}$ D. Laney, Infonomics: How to Monetise, Manage and Measure Information as an Asset for Competitive Advantage, Gardner, Inc., New York 2018. 
proposed approach increases the profit by minimum $15 \%$ in comparison with passive and active risk management, respectively. In addition, a mixed strategy for inventory management of distribution centres is suggested to improve the profits of global Business chain and data valuation statistics subject to substantial risks.

Figure 1. Evaluation model - predictable data (business model)

\begin{tabular}{|c|c|c|c|c|c|c|c|}
\hline $\mathrm{M}$ & $\mathrm{T}$ & W & $\mathrm{T}$ & $\mathrm{F}$ & $S$ & $S$ & \\
\hline & 1 & 2 & 3 & 4 & 5 & 6 & \\
\hline 7 & 8 & 9 & & 11 & 12 & 13 & by data valuation \\
\hline 14 & 15 & 16 & 17 & 18 & 19 & 20 & \\
\hline 21 & 22 & 23 & 24 & 25 & 26 & 27 & \\
\hline 28 & 29 & 30 & 31 & & & & \\
\hline
\end{tabular}

Business processes design optimisation is known as the problem of creating feasible business processes while optimising their criteria such as resource cost and execution time. In this study, the authors propose a forecast multi-criteria approach based on a modified forecast algorithm for generating optimised business processes. The main contribution of this work is a framework capable of:

1) generating business processes using an enhanced version of the forecast algorithm,

2) verifying the feasibility of each business process and

3) selecting data evaluation systems as an optimal solution in a multi-criteria optimisation environment up to predetermined three criteria, with use of effectual meetings. The experimental results have shown that the model proposal generates efficient business processes outcomes (measurable and recognised) of high quality in terms of qualitative parameters compared with the existing solutions.

Today's leadership methodology understands that leadership often works more effectively as a collaborative process. As part of this process, there are specific informal leaders who are willing and able to participate in strategy formation and execution. According to the four-step data evaluation, informal leaders are most often closest to those that are tasked with enacting any type of strategy so they can help shape and implement it within their collaborative leadership role. By doing so, the main leader can leverage people who become champions of the strategy process. 
This forecast algorithm approach is suitable for the adaptive design of a powerful management system. The design objective is evidence-oriented and the optimal controller parameters are designed in a coordinated way. To show the adaptive capabilities of the proposed approach, simulation results are presented for various management conditions with parameter variations. Also, the results are compared with a single objective GA approach to show the superiority of the proposed solution.

\section{Data Valuation Statistics}

To become more effective, leader-managers must learn how to influence others with the intent of effectively motivating them. Leaders possess qualities that make others want to follow them. The standard definition of leadership is the process of influencing other people's behaviour towards achieving a predetermined goal. It is imperative to note that leadership also involves:

- data traceability,

- forecasting,

- data classification,

- data valuation statistic.

Leadership traits are physical or personality characteristics that differentiate leaders from their subordinates. There have been many attempts to define these qualities over the years and perceptions of what distinguishes leaders have been changing. A simulation-based forecast algorithm approach is proposed for the operational planning of global Business chain and data valuation statistics subject to substantial risks. The systematic proactive Data Valuation Statistics process of global Business chain and data valuation statistics increases business profits.

As the popularity of Forecasting methods is growing every day, industries view iterative, forecast and incremental software development as the 'modern' replacement of the business model. Organisations are now being shifted from traditional software development methodologies like waterfall models to Data Valuation Statistics.

Data Valuation Statistics is a process in an area frame based on a stratified multi-stage design that uses probability sampling. The total sample is composed of several independent samples, called management groups because each group can be, or is, replaced. Cross-sectional weights account for unequal probabilities of sample selection. To account for the complex sample design, the bootstrap technique was used to estimate coefficients of variation and confidence intervals as well as to test for the statistical significance of the differences.

This methodology focuses on the delivery of data valuation in the place of delivery of full featured software. This facilitates faster delivery of ideas 
Figure 2. Inter-correlation bonds and algorithms (real example)

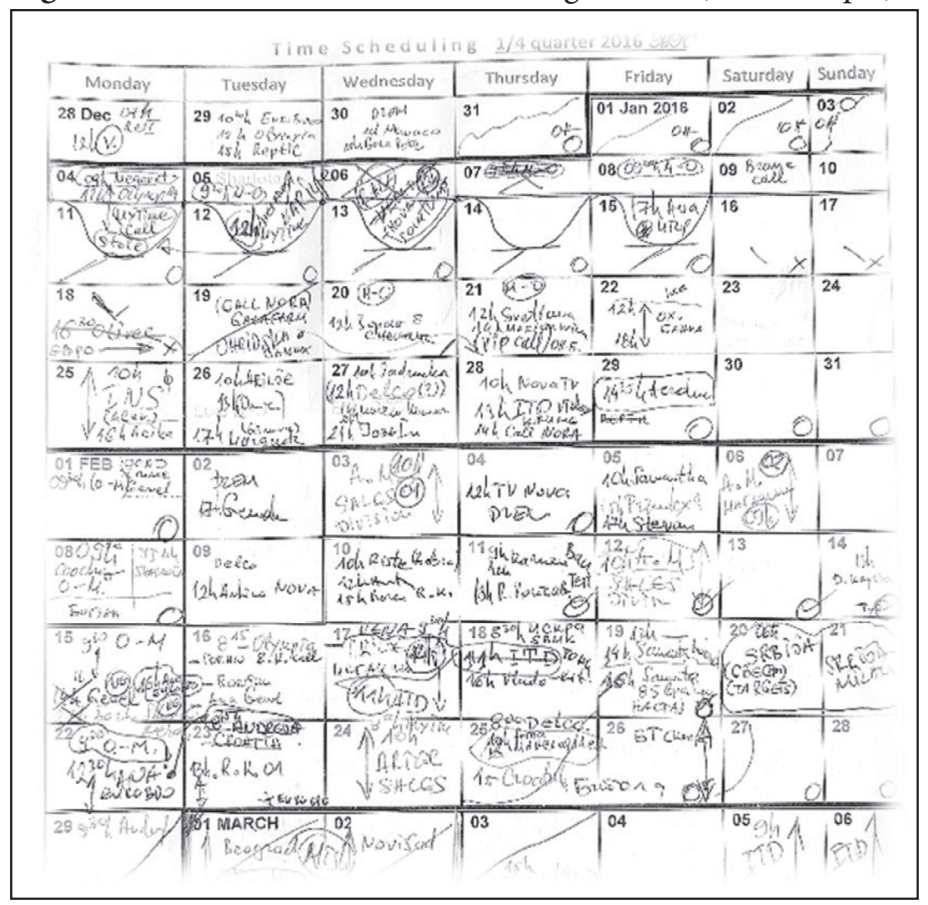

to form into products. By releasing data valuation to its users, organisations get quick and faster feedback from the customer. Thus, they can predict market in a very fast and efficient manner. The full release of the product is divided into small iterations called data modelling portions. Each portion contains one or more fully developed and complete features or requirements. The planning of the entire data modelling portion, which shows how many and what stories will be part of different data modelling portions, is called release planning. This planning depends on effort, team capacity, business value and technical precedence between different stories. The aim is to deliver maximum business value as soon as possible. A mixed strategy for inventory management of distribution centres improves the profit performance of global Business chain and data valuation statistics subject to substantial risks.

Even if the result of alternatives do not seem to provide enough insight on decision-making, by applying the genetic algorithm method we can derive the overall solution through making the best use of them. In general, the relative importance of criteria is ambiguous and the scores are imprecise. It suggests that, in such cases, the Forecasting algorithm method is useful. In this study, a Business chain and data valuation statistic network model has been proposed using an analytical hierarchy process and Business algorithm approach. This approach is used to synthesise the opinions of decision makers to identify the weight of each alternative. This demon- 
strates the advantage of being able to capture the decision maker's opinion and intuition in solving business challenges in a structured manner through data valuation. Further development of this approach could mark an improvement in the determination of a predictable scenario of each alternative and handling the uncertainty level of the decision-making problem.

The Forecasting capitalisation process identifies the following basic traits, which remain relevant:

- Traceability. Managers attract attention by presenting data as a strong vision and commitment to accomplishment.

- Content. Leaders use exceptional data and communication skills that make visions tangible to others. (ownership).

- Trust. Leaders exhibit clear focus and consistent behaviour, which generates trust by presenting objective evidences through data valuation statistics.

- Capitalisation. Leaders know their limitations but remain optimistic by leading the results and using capitalisation methods in past and legacy systems.

\section{Conclusion}

In this study, we have presented a study of Business Communication Algorithms, Service Scenario Design and Data Valuation Statistics as an improved multi-objective forecast algorithm that employs an enhanced management assignment strategy compared to Business advanced processes as well as new techniques for archive data and density-based Data Valuation Statistics. The key conclusion are: it offers better results on all decisions; has fastest convergence; probably due to its higher intensity, there are difficulties on some decisions because it does not always keep the boundary solutions and those with higher dimensional objective spaces; it seems to have advantages over business processes.

The paper emphasises that many differences are only revealed for more objectives. In higher-dimensional objective spaces, the number of predictable solutions increases rapidly. This presents a much greater challenge, e.g. for the archiving strategies and in general for the algorithms, of keeping the desired convergence properties and at the same time maintaining a good distribution of solutions. Exactly this observation was the reason why great importance was attached to accurate density estimation with the design of Business Communication Algorithms. Service Scenario Design, 3-cycled meeting scheduling and Data Valuation Statistics are faster in terms of worst-case complexity, the issue of density estimation becoming the more important, the more objectives are involved. Furthermore, it becomes obvious that it is necessary to trace the performance over time to keep track 
of the dynamic behaviour of the algorithms. Specifically, they are likely to differ in convergence velocity or reveal effects such as premature convergence or stagnation, which cannot be seen in a static analysis after some arbitrary running time.

\section{Bibliography}

Benvenuto N., Cherubini G., Algorithms for Communications Systems and their Applications, 1st ed., John Wiley \& Sons Ltd, The Atrium, Southern Gate, Chichester, West Sussex 2002.

Carroll J.M. (ed.), Scenario-Based Design: Envisioning Work and Technology in System Development, John Wiley \& Sons, Inc. New York 1995.

Koller T., Goedhart M., Wessels D., Valuation: Measuring and Managing the Value of Companies, 6th ed., McKinsey \& Company Inc., John Wiley \& Sons, New Jersey 2015.

Laney D., Infonomics: How to Monetise, Manage and Measure Information as an Asset for Competitive Advantage, Gardner, Inc., New York 2018.

Abstract

Among all search and optimisation techniques, the development of Business Communication Algorithms (BCA) has been very important in the last decade. BCAs are a set of modern forecasting models used successfully in many business applications with great complexity. Its success in solving difficult decisions has been the engine of a field known as Leadership Design Scenario (LDS). The benefits of using LDC techniques come mostly from flexibility gains as well as their matching the target together with organisational behaviour. Nowadays, LDC is considered an adaptable concept for decision-making, especially complex optimisation decisions. This vision is an alternative to some existing business processes and shows BCA and LDC as a collection of similar algorithms ready to be used to solve any business problem.

Keywords: Data Valuation Statistics, advanced business processes, Business Communication Algorithms, Service Scenario Design

\section{Analiza algorytmów komunikacji w biznesie, projektu scenariusza usługowego oraz danych statystycznych dotyczących wyceny danych (innowacje, model biznesowy)}

Streszczenie

Wśród technik wyszukiwania i optymalizacji w ostatnim dziesięcioleciu bardzo ważny jest rozwój algorytmów komunikacji w biznesie (BCA). Stanowią one zestaw nowoczesnych modeli prognozowania $\mathrm{z}$ powodzeniem wykorzystywanych $\mathrm{w}$ wielu wysoce złożonych sytuacjach biznesowych. Ich przydatność w zakresie podejmowania trudnych decyzji napędza rozwój dziedziny zwanej scenariuszem projektowania przywództwa (LDS). Korzyści ze stosowania technik LDC dotyczą głównie zwiększonej elastyczności oraz ich dopasowania do obiektywnego celu w połączeniu z zachowaniem organizacji. Obecnie LDC uznaje się za adaptowalną koncepcję podejmowania decyzji, zwłaszcza tych złożonych, dotyczących optymalizacji. Ujęcie takie stanowi alternatywę dla nie- 
których istniejących procesów biznesowych i pokazuje BCA oraz LDC jako zbiór podobnych algorytmów, które można zastosować w dowolnym problemie biznesowym.

Słowa kluczowe: dane statystyczne dotyczące wyceny danych, zaawansowane procesy biznesowe, algorytmy komunikacji w biznesie, projekt scenariusza usługowego 